\title{
Test reproducibility of the API (20E), Enterotube, and Pathotec systems
}

\author{
B. HOLMES, W. R. WillCOX, S. P. LAPAGE, AND H. MALNICK \\ From the National Collection of Type Cultures, Central Public Health Laboratory, Colindale, London \\ NW95HT
}

SUMMARY Thirty-three strains of bacteria (30 Enterobacteriaceae and one strain each of Aeromonas formicans, A. hydrophila, and Plesiomonas shigelloides) were tested three times in each of 27 conventional tests and in the API, Enterotube, and Pathotec systems. The results obtained were analysed for test reproducibility within each kit, correlation of the kit tests with the equivalent conventional media, and the identification of the strains by the kits. Difficulties in evaluation and comparison of identifications are discussed. A practical evaluation of the kits was also made.

Several commercially produced kit systems now available for the identification of Enterobacteriaceae have been studied both for correlation of kit test results with the corresponding conventional test results and for success in identification of strains. When the laboratory work for the present study was carried out (in January 1975) only three kits appeared to be used relatively widely in the United Kingdomthe API (20E), Enterotube, and Pathotec systems. Of these three kit systems, the API and Enterotube have been compared with each other and with conventional media by Bisgaard et al. (1974), by Willis and Cook (1975), and by Hayek and Willis (1976). Nord et al. (1974) compared the API, Enterotube, Pathotec, Auxo Tab, and R/B kits with each other and with conventional media, while Smith (1975) compared the API, Enterotube, and Minitek kits with each other and with conventional media. Moussa (1975) compared the API, Enterotube, and Pathotec systems with each other and with conventional media.

The results of microbiological tests are not completely reproducible even when carefully repeated in a single laboratory (Sneath and Johnson, 1972; Snell and Lapage, 1973; Sneath, 1974). The variation is greater for the results obtained on the same strains in different laboratories because of differences in media and methods for nominally the same tests (Lapage et al., 1973). Commercially produced kit systems, each quality-controlled at a central source, should show improved reproducibility between laboratories which should approach the repro-

Received for publication 12 July 1976 ducibility within laboratories. The reproducibility of test results of kit systems has, however, been examined by few investigators. Brooks et al. (1974) examined 15 known strains of Enterobacteriaceae, each five times in the API system. Each test was therefore performed 75 times and the reliability of correct results ranged from $71 / 75$ to $75 / 75$ with an average of $97.7 \%$. An extensive investigation of test reproducibility in the API 20E system was carried out by Butler et al. (1975). In phase I of their study 110 strains were each tested twice. Of $2200(20 \times 110)$ pairs of test results, $85(3.9 \%)$ were in disagreement. The test showing lowest reproducibility was citrate utilisation with $89 \%$ reproducibility, that is, 12 disagreements in 110 pairs of test results. Reproducibility of tests in the Enterotube system does not appear to have been studied, but Cameron (1974) tested a single Klebsiella isolate 12 times in the Pathotec system and obtained entirely consistent test results. The best way of comparing the results of different studies of test reproducibility is to express them in terms of the estimated probabilities of erroneous test results (Sneath and Johnson, 1972). Within one laboratory the average probability of errors for conventional biochemical tests is typically $2-4 \%$ with probabilities as high as $12 \%$ for some tests; the probability of errors between laboratories for such tests is typically $6-10 \%$ on average with probabilities of $20-30 \%$ for some tests (Lapage et al., 1973; Sneath, 1974). The results of Butler et al. (1975) on the API 20E tests indicate a probability of errors of about $2 \%$ with $6 \%$ for the citrate utilisation test.

We have compared the three diagnostic kits most 
widely used in this country at the time of our study, together with conventional media, for reproducibility of test results within each system, agreement of kit test results with the results obtained in the corresponding conventional media, and success rate in identification by the three kits. In any study such as this, however, it must be remembered that not all the test methods may be directly comparable either between kits or between kits and conventional methods. The expected results may differ for the same test in the different kit systems, which is unimportant as long as each kit gives internal consistency and reproducibility.

\section{Material and methods}

\section{ORG ANISMS}

Thirty-three strains of bacteria (30 Enterobacteriaceae and one strain each of Aeromonas formicans, A. hydrophila, and Plesiomonas shigelloides) were used in this study (Table 1). The majority of the strains (29) were reference cultures maintained in the National Collection of Type Cultures (NCTC), Colindale. The identity of all the strains was confirmed on the results of conventional tests using the computer identification method of Lapage et al. (1973).

\section{TESTS AND METHODS}

The biochemical tests which are performed in each of the kit systems are given in Table 2, which also shows the conventional tests carried out on each strain; all tests were incubated at $37^{\circ} \mathrm{C}$.

The API 20E kit consists of plastic cupules containing dehydrated media which are inoculated with a suspension of the test organism in distilled water and incubated for 18-24 h. The Enterotube consists of a plastic tube within which are compartments of media in agar slopes; the media are inoculated from a single colony by withdrawing a pre-sterilised inoculating wire (which is part of the kit) through the compartments. The Enterotube is also incubated for $24 \mathrm{~h}$, although the manufacturer states that slow lactose-fermenting strains may require longer incubation. The Pathotec system consists of reagent-impregnated strips, which are incubated for $4 \mathrm{~h}$ only, standing in test tubes containing a dense suspension of the test organism in a saline solution, thereby testing for preformed enzymes. Expected results for motility at $37^{\circ} \mathrm{C}$ are included in the identification table provided by the manufacturer of the Pathotec system which recommends that the test be carried out by microscopic examination of a drop of suspension from the indole tube before it is tilted to mix the suspension with the indole reagent, or from the $\mathrm{H}_{2} \mathrm{~S}$ tube. We determined motility at $37^{\circ} \mathrm{C}$ from a 'hanging-drop' preparation of the organism cultured in nutrient broth instead of the methods recommended by the kit manufacturer, therefore this test is not included in Table 2. All kit tests were performed according to the manufacturers' instructions which give full details of the kits and how they are to be inoculated and incubated, and the tests interpreted.

All conventional tests were recorded at or up to five days except where stated in parentheses in the text below. The following tests were carried out using the media and methods described by Cowan (1974); particular methods where several are given and modifications to the method or medium appear in parentheses: $\beta$-galactosidase production (ONPG test; 2 days), decarboxylases (method 1 ; bromocresol purple indicator in place of bromothymol blue), citrate utilisation (method $2 ; \mathrm{Oxoid}$ ), $\mathrm{H}_{2} \mathrm{~S}$ production

Table 1 Strains examined

\begin{tabular}{|c|c|c|c|}
\hline Designation & Strain No. & Designation & Strain No. \\
\hline $\begin{array}{l}\text { Citrobacter freundii } \\
\text { Citrobacter koseri } \\
\text { Edwardsiella tarda } \\
\text { Enterobacter aerogenes } \\
\text { Enterobacter cloacae } \\
\text { Erwinia herbicola } \\
\text { Escherichia coli } \\
\text { Hafnia alvei } \\
\text { Klebsiella aerogenes } \\
\text { Klebsiella ozaenae } \\
\text { Klebsiella pneumoniae } \\
\text { Klebsiella rhinoscleromatis } \\
\text { Proteus mirabilis } \\
\text { Proteus morganii } \\
\text { Proteus rettgeri } \\
\text { Proteus vulgaris } \\
\text { Providencia alcalifaciens }\end{array}$ & $\begin{array}{l}\text { NCTC } 6071 \\
\text { NCTC } 10786 \\
\text { NCTC } 10397 \\
\text { CL.546/73 } \\
\text { NCTC } 10005 \\
\text { NCTC } 10500 \\
\text { NCTC } 9001 \\
\text { NCTC } 6578 \\
\text { NCTC } 8172 \\
\text { NCTC } 9659 \\
\text { NCTC } 5056 \\
\text { NCTC } 5046 \\
\text { NCTC } 6197 \\
\text { NCTC } 2815 \\
\text { NCTC } 8893 \\
\text { NCTC } 10034 \\
\text { NCTC } 6933\end{array}$ & $\begin{array}{l}\text { Providencia stuartii } \\
\text { Salmonella choleraesuis } \\
\text { Salmonella gallinarum } \\
\text { Salmonella pullorum } \\
\text { Salmonella typhi } \\
\text { Salmonella typhimurium (sub-genus I) } \\
\text { Salmonella greenside (sub-genus II) } \\
\text { Salmonella arizonae (sub-genus III) } \\
\text { Salmonella bonaire (sub-genus IV) } \\
\text { Serratia liquefaciens } \\
\text { Serratia marcescens } \\
\text { Shigella sonnei } \\
\text { Shigella dysenteriae } \\
\text { Aeromonas formicans } \\
\text { Aeromonas hydrophila } \\
\text { Plesiomonas shigelloides }\end{array}$ & $\begin{array}{l}\text { CL142/71 } \\
\text { NCTC } 5736 \\
\text { NCTC } 10532 \\
\text { NCTC } 5776 \\
\text { NCTC } 786 \\
\text { NCTC } 5710 \\
\text { NCTC } 9936 \\
\text { NCTC } 8297 \\
\text { E281 } \\
\text { NCTC } 10862 \\
\text { NCTC } 2446 \\
\text { NCTC } 10352 \\
\text { NCTC } 9347 \\
\\
\text { CL225/69 } \\
\text { NCTC } 7810 \\
\text { NCTC } 10363\end{array}$ \\
\hline
\end{tabular}

NCTC = National Collection of Type Cultures

$\mathrm{CL}$ or $\mathrm{E}=$ Stock cultures which have been submitted to the NCTC for computer-assisted identification 
Table 2 Tests in each kit system and conventional tests performed

\begin{tabular}{|c|c|c|c|c|}
\hline \multirow[t]{2}{*}{ Test for: } & \multicolumn{3}{|l|}{ System } & \multirow[t]{2}{*}{ Conventional tests } \\
\hline & $A P I 20 E$ & Enterotube & Pathotec & \\
\hline$\beta$-galactosidase production (ONPG test) & + & - & - & + \\
\hline Arginine dihydrolase & + & - & - & + \\
\hline Lysine decarboxylase & + & + & + & + \\
\hline Ornithine decarboxylase & + & + & - & + \\
\hline Citrate utilisation & + & + & - & + \\
\hline $\mathrm{H}_{2} \mathrm{~S}$ production & + & + & + & + \\
\hline Urease production & + & + & + & + \\
\hline $\begin{array}{l}\text { Deamination of tryptophan or phenylalanine } \\
\text { (TDA and PPA tests respectively) }\end{array}$ & + & + & + & + \\
\hline Indole production & + & + & + & - \\
\hline Acetoin production & + & - & - & + \\
\hline Gelatin liquefaction & + & - & - & + \\
\hline Acid from glucose or dextrose & + & $T$ & - & + \\
\hline Gas from glucose or dextrose & - & + & - & + \\
\hline Acid from mannitol & $\div$ & - & - & + \\
\hline Acid from inositol & + & - & - & + \\
\hline Acid from sorbitol & + & - & - & + \\
\hline Acid from rhamnose & + & - & - & + \\
\hline Acid from sucrose & + & - & - & + \\
\hline Acid from melibiose & + & - & - & + \\
\hline Acid from amygdalin & + & - & - & + \\
\hline Acid from arabinose & $\div$ & - & - & + \\
\hline Acid from lactose & - & + & - & + \\
\hline Acid from dulcitol & - & + & - & + \\
\hline Nitrate reduction & + & - & + & + \\
\hline Cytochrome oxidase production & - & - & + & + \\
\hline Malonate utilisation & - & - & + & + \\
\hline Aesculin hydrolysis & - & - & + & + \\
\hline
\end{tabular}

$+=$ test contained in kit system

- $=$ test not contained in kit system

(triple sugar iron agar; Oxoid), urease production (method 1), production of phenylpyruvic acid (PPA test; method $1 ; 2$ days; L-phenylalanine $1.0 \mathrm{~g}$ in place of DL-phenylalanine $2.0 \mathrm{~g}$ ), indole production (method $2 ; 2$ days), acetoin production (V-P test; method $2 ; 2$ days), gelatin liquefaction (method 2 ), acid and gas from carbohydrates (Andrade's indicator; final concentration of all carbohydrates $0.5 \mathrm{~g} / 100 \mathrm{ml}$ ), nitrate reduction (method 1; tested with reagents of Crosby, 1967), cytochrome oxidase production (method $1 ; 1$ day), malonate utilisation (method 1; 2 days), and aesculin hydrolysis (agar method).

\section{REPRODUCIBILITY OF THE TESTS}

Three investigators separately tested each strain in each test kit so that each test on each strain was carried out three times. As the results were being recorded, all three sets of tests on each strain were compared so that differences in test results were not due to differences in interpretation by the three investigators but were due to actual differences in the colours of the reactions. Difficulties in interpretation of colour reactions were few in the API and Pathotec systems. For the Enterotube system, however, a colour chart was provided which was sometimes misleading. Lysine and ornithine, for example, when positive never gave the deep purple colour shown on the chart; however, in this study even if the medium turned only slightly purple it was considered positive. In the Enterotube system the phenylalanine deamination (PPA) test medium, which initially is green in colour, is expected to go a darker green in the case of a weak positive reaction and to a dark brown or black colour for a strongly positive reaction. Strains expected to give a positive result in this test did develop the dark brown or black colour of a strongly positive reaction. In most of the other strains, however, for which a negative result was expected, the darker green colour of a weak positive reaction in the PPA test was observed. This colour was therefore ignored and considered negative in all comparisons and identifications. As far as could be determined, all the kits and conventional media used in this study were manufactured from single batches.

A convenient way of expressing test reproducibility is the probability of erroneous test results (Sneath and Johnson, 1972). In the present study each test was repeated three times, and for simplicity in presentation and for testing the significance of the results it is assumed that if the three results were consistent $(+++$ or ---$)$ then all three results were correct, and if the results were inconsistent (eg, 
++- or --+$)$ the single minority result was an error. For the results of three replicate tests presented in this way an estimate of the probability of an erroneous test result, which is not biased by these assumptions, is given by $C$,

$$
C=\frac{1}{2}(1-\sqrt{1-4 E / N)}
$$

where $E$ is the number of errors observed, $N$ is the total number of test results, and $C$ is termed the corrected error rate. This formula is obtained from formulae (4) and (14) of Sneath and Johnson (1972).

COMPARISON OF KIT TEST RESULTS WITH CONVENTIONAL MEDIA RESULTS

To compare the results of the kit tests with the results in the corresponding conventional media each set of three repeated tests was treated as a single test, and if the repeated results were inconsistent the majority result was taken. It is shown below that, for the results of this study, this procedure meant that the occurrence of erroneous test results had little effect on the comparison of results between testing methods.

\section{IDENTIFICATION OF STRAINS}

Although the laboratory work was carried out in January 1975 , the identification of the strains has been carried out on the latest schemata available in the United Kingdom in October 1976 for each of the three kits tested.

The strains of Aeromonas formicans, A. hydrophila, and Plesiomonas shigelloides were not included in the calculation of identification rates since provision was not made for their identification in all of the kits in October 1976. For the API system, identification was achieved by an exact match of the results of an unknown strain against a named pattern held in a register in the form of a numerical code referred to by the manufacturer as the 'Profile Index' (ours was dated 1975), and the patterns of test results not listed in the 'Profile Index' were then submitted to the complementary API Computer Identification Service. In the Enterotube system a similar match was carried out against named patterns listed in the 'Encise' system (ours was dated 1973-1147 version). The Pathotec scheme employed a flowchart and identification table (ours was dated August 1972). The manufacturer of the Pathotec system gave no specific instructions on how to use the identification table so we adopted the following procedure. If the strain gave oxidase negative and nitrate positive reactions (which was the case with the majority of strains examined) the results of all the Pathotec tests together with motility at $37^{\circ} \mathrm{C}$ were compared with the entries in the identification table. A set of results was taken to match a taxon in the identification table if the results agreed exactly with the entries for that taxon, taking \pm entries in the table as + and $\mp$ entries as - , or if the results differed with the entries for the taxon in just one instance in which the result was + and the entry $\mp$ or the result - and the entry \pm . Any taxa matched by the results in this way were taken as identifications by the Pathotec scheme. For strains giving other patterns of results in the oxidase and nitrate tests the identification indicated by the flowchart was taken. For some identifications in the API, Enterotube, and Pathotec systems additional conventional tests as well as serological investigations may be required to further or confirm the identification. The additional tests were not carried out in this study; if the system indicated the correct taxon as one of the possible identities this was counted as a correct identification. If serological investigation would have prevented a misidentification then that pattern of results was counted as not identified.

Since the 30 strains of enterobacteria tested gave inconsistent results in certain tests in the three kit systems, each pattern obtained was considered separately for identification; identification was thus based on 90 patterns for each system.

\section{Results}

REPRODUCIBILITY OF THE TESTS

The number of errors in reproducibility of the tests within systems is given in Table 3 . The difference in the proportion of errors between the three kit systems was not significant $\left(\chi^{2}\right.$ test, $\left.\mathrm{P}>0 \cdot 1\right)$. The kit systems taken together had a significantly higher proportion of errors than the conventional tests $\left(\chi^{2}\right.$ test, $\left.\mathrm{P}<0.005\right)$.

Individual tests showing poor reproducibility are given in Table 4. The Pathotec aesculin test had a significantly higher proportion of errors than the other tests in the system (Cochran $Q$ test, $P<0.005$; Cochran, 1950) as did the Enterotube gas from dextrose test (Cochran $Q$ test, $P<0.01$ ). The results for the API citrate utilisation test suggest that this test may show a higher proportion of errors than the other API tests although the difference was not statistically significant (Cochran $Q$ test, $P>0 \cdot 25$ ).

COMPARISON OF KIT TEST RESULTS WITH CONVENTIONAL MEDIA RESULTS

Earlier we stated that in order to compare the results of the kit tests with the results in the equivalent conventional media each set of three repeated tests was treated as a single test and if the repeated results were inconsistent the majority result was taken. Table 3 shows that over all the tests the corrected error rate was less than $2 \%$. For a $2 \%$ probability of erroneous results there is a $99.9 \%$ probability 
that the above procedure will give the true result of a test and so, for the error rate observed here, the occurrence of erroneous test results should have little effect on the comparison of results between methods. The correlation of kit test results with conventional media is given in Table 5 . The differences in proportions of disagreements with conventional media between the three kit systems are not significant ( $\chi^{2}$ test, $P>0 \cdot 5$ ).

Individual tests showing a low rate of agreement with conventional media are given in Table 6 . The five tests in the table had a significantly higher proportion of disagreements than the majority of tests (Cochran $Q$ test, $P<0.05$ ). None of these tests had an error rate of more than $2.1 \%$ so again the occurrence of erroneous test results should have little effect on the comparison of the test results obtained in a kit system with the results of the corresponding conventional methods for these individual tests.

IDENTIFICATION OF STRAINS

Identification of strains of Enterobacteriaceae by the three kit systems is summarised in Table 7.

Table 3 Reproducibility of tests within systems

\begin{tabular}{|c|c|c|c|c|}
\hline System & $\begin{array}{l}\text { No. of } \\
\text { tests in } \\
\text { system }\end{array}$ & $\begin{array}{l}\text { Total no. } \\
\text { of test } \\
\text { results }\end{array}$ & $\begin{array}{l}\text { No. of } \\
\text { errors }\end{array}$ & Corrected error rate ${ }^{1}$ \\
\hline $\begin{array}{l}\text { Conventional } \\
\text { API } \\
\text { Enterotube } \\
\text { Pathotec }\end{array}$ & $\begin{array}{l}27 \\
21 \\
11 \\
10\end{array}$ & $\begin{array}{r}2673 \\
2079 \\
1089 \\
990\end{array}$ & $\begin{array}{l}20 \\
32 \\
14 \\
23\end{array}$ & $\left\{\begin{array}{l}0.8 \%(0.5 \%-1 \cdot 1 \%) \\
1.7 \%(1 \cdot 3 \%-2 \cdot 1 \%)\end{array}\right.$ \\
\hline
\end{tabular}

$195 \%$ confidence intervals are shown for corrected error rates

Table 4 Individual tests showing poor reproducibility

\begin{tabular}{llll}
\hline Test & $\begin{array}{l}\text { No. of } \\
\text { test results }\end{array}$ & $\begin{array}{l}\text { No. of } \\
\text { errors }^{1}\end{array}$ & $\begin{array}{c}\text { Corrected } \\
\text { error rate }^{2}\end{array}$ \\
\hline Aesculin-Pathotec & 99 & 10 & $11 \%(5 \%-18 \%)$ \\
Dextrose gas-Enterotube & 99 & 6 & $6 \%(2 \%-12 \%)$ \\
Citrate-ADI & 99 & 5 & $5 \%(2 \%-11 \%)$ \\
\hline
\end{tabular}

${ }^{1}$ Other tests gave 0 to 3 errors in 99 results

$295 \%$ confidence intervals are shown for corrected error rates

Table 5 Correlation of tests with conventional media within systems

$\begin{array}{lllll}\hline \text { System } & \begin{array}{l}\text { No. of } \\ \text { tests in } \\ \text { system }\end{array} & \begin{array}{l}\text { Total no. } \\ \text { of tests }\end{array} & \multicolumn{2}{l}{\text { Disagreements with conventional }} \\$\cline { 4 - 5 } & 21 & 693 & \text {$\left.No. } & \text { Rate } \\ \hline \text { API } & 21 & 363 & 25 \\ \text { Enterotube } & 11 & 330 & 19\end{array}\right\} \begin{aligned} & 7 \%(6 \%-9 \%) \\ & \text { Pathotec }\end{aligned}$

$195 \%$ confidence interval is shown for rate of disagreement
Table 6 Individual tests showing poor agreement with conventional media

\begin{tabular}{llll}
\hline \multirow{2}{*}{ Test } & $\begin{array}{l}\text { No. of } \\
\text { test } \\
\text { results }\end{array}$ & \multicolumn{2}{l}{ Disagreements with conventional } \\
\cline { 2 - 4 } & 33 & No. $^{1}$ & Rate $^{2}$ \\
\hline Amygdalin-API & 33 & 8 & $24 \%(9 \%-43 \%)$ \\
Melibiose-API & 33 & 7 & $24 \%(9 \%-43 \%)$ \\
Urease-Pathotec & 33 & 6 & $21 \%(8 \%-41 \%)$ \\
Lysine-Enterotube & 33 & 6 & $18 \%(6 \%-37 \%)$ \\
Arginine-API & 33 & $18 \%(6 \%-37 \%)$ \\
\hline
\end{tabular}

1Other tests gave 0 to 4 disagreements in 33 results

$295 \%$ confidence intervals are shown for rates of disagreement

Table 7 Identification of strains by the kits

\begin{tabular}{lcccc}
\hline System & $\begin{array}{l}\text { No. of } \\
\text { patterns }\end{array}$ & $\begin{array}{l}\text { Correctly } \\
\text { identified }\end{array}$ & $\begin{array}{l}\text { Not } \\
\text { identified }\end{array}$ & $\begin{array}{l}\text { Incorrectly } \\
\text { identified }\end{array}$ \\
\hline $\begin{array}{l}\text { API } \\
\text { (Profile Index alone) }\end{array}$ & 90 & $57(63 \%)$ & $33(37 \%)$ & $0(0 \%)$ \\
$\begin{array}{l}\text { API } \\
\text { (Profile Index + computer) }\end{array}$ & 90 & $83(92 \%)$ & $7(8 \%)$ & $0(0 \%)$ \\
$\begin{array}{l}\text { Enterotube } \\
\text { (Encise system) }\end{array}$ & 90 & $63(70 \%)$ & $1(1 \%)$ & $26(29 \%)$ \\
$\begin{array}{l}\text { Pathotec } \\
\text { (Diagnostic table) }\end{array}$ & 90 & $58(64 \%)$ & $21(23 \%)$ & $11(12 \%)$ \\
\hline
\end{tabular}

\section{Discussion}

There was no significant difference in test reproducibility between the API, Enterotube, and Pathotec systems. The reproducibility of the kit tests taken together was significantly worse than that of the conventional media used in this study but the estimated probability of erroneous test results for kit tests of $1.7 \%$ is still low in comparison with the probabilities of $2-4 \%$ found in other studies using conventional tests (see Introduction). The probability of errors for the conventional tests in this study $(0.8 \%)$ is particularly low, probably because they are well-established tests in routine use in our laboratory. The overall rate of disagreement between kit tests and conventional tests of $7 \%$ is within the typical range of between-laboratory probability of errors for conventional tests of 6-10\% (see Introduction).

In drawing conclusions of practical importance from the overall identification rates it must be remembered that in different applications of the systems the frequency of occurrence of the various taxa in the material examined will vary widely, and our results are therefore not directly comparable with those results likely to be obtained in the routine diagnostic laboratory. The results presented here suggest that the identification scheme of the Enterotube system is too lenient in comparison with the other systems as, although it identified a high proportion of the strains, the proportion of incorrect 
identifications was also high. Identification rates by kit systems are difficult to compare as the level of identification varies between kits. Also, identification is achieved by different numbers of tests on each strain in the API, Enterotube, and Pathotec systems as all three systems may require additional conventional tests to further or confirm the identification.

Our results for reproducibility and agreement with conventional methods are in a similar range to those of Nord et al. (1974), Butler et al. (1975), and Moussa (1975) although the latter author found that some tests in the API and Pathotec systems showed more disagreement with conventional methods than we found (eg, API citrate 54.3\% disagreement with conventional, Pathotec lysine $61.9 \%$ disagreement with conventional, while the corresponding figures for these two tests in our study were $6 \%$ and $9 \%$ respectively). Our estimated probability of erroneous test results for all the API $20 \mathrm{E}$ tests is $1.6 \%$ and for the API citrate test is $5 \%$ (Table 4), in good agreement with the corresponding figures of $2 \%$ and $6 \%$ respectively determined from the results of Butler et al. (1975). The latter authors attempted to determine possible reasons for lack of reproducibility in their repeated testing of strains in the API 20E system. We did not attempt this but can exclude observer interpretation (as all tests for which discrepant results were recorded were checked for differences in colour), incubation time (since this was kept constant), and batch variation (as all the kits and conventional media came, as far as we could tell, from single batches); one possible reason is size of inoculum which we did not standardise. Moussa (1975) did not include identification rates for his strains but those of Nord et al. (1974), Smith (1975), and Hayek and Willis (1976) were higher than ours for each kit, possibly because these authors examined strains from a smaller range of taxa compared with the 30 used in this study. The routine diagnostic laboratory would expect that the majority of its strains would be drawn from a smaller range of taxa than those used in this study, which included rare taxa, and so higher identification rates were found by Nord et al. (1974), Smith (1975), and Hayek and Willis (1976) who carried out their tests in routine dignostic laboratories. Nord et al. (1974) found that Enterotube gave the highest identification rate of any of the kit systems they examined but they did not discuss the misidentification rates. In our study the API system achieved the highest identification rate when used in conjunction with a computerassisted identification scheme; this illustrates the value of computers in identification (Table 7). No doubt other kit system manufacturers will develop their own computer-assisted identification schemes which will hopefully allow an increase in the identification rate and a reduction of any misidentification rate. In addition, the API system might be expected to achieve a higher identification and lower misidentification rate as, of the three kits examined here, it has the largest number of tests available for differentiation.

Technically, all the systems had advantages and disadvantages. The Enterotube, for example, was the most speedily inoculated and even a Bunsen burner was not necessary. The API system was also quickly inoculated once a suspension had been made; the Pathotec system was perhaps most timeconsuming as each test strip had to be placed into a separate test-tube containing a suspension of the organism, but a sterile procedure was not required as one was looking for pre-formed enzymes; a dense suspension of the test organism would therefore give best results. If one wished to check the purity of the culture tested this would be a simple procedure with the API and Pathotec systems where a bacterial suspension is used; difficulty would be experienced with the Enterotube, however, due to the inaccessibility of the media compartments.

The Pathotec system had two advantages over the API and Enterotube systems; it could be read after $4 \mathrm{~h}$ incubation whereas the other two systems required 18-24 h. Also it is possible to repeat a single test with the Pathotec system whereas repetition of any test in the other two kit systems requires use of the whole kit. Of the three kits, the Pathotec system was perhaps the least safe to use as aerosols could be more readily created than with the other two kits. Hayek and Willis (1976) drew attention toa dangerous practice in the Enterotube where the manufacturer recommends that the indole reagent be added to the indole test compartment by means of a syringe and needle.

The Pathotec oxidase test was considered to have no advantages over conventional methods. Positive test results were not as clear as by conventional means, and since the test could be carried out only twice on each strip it would be easier to carry out the test by conventional means when one has more than one or two strains to identify with the Pathotec system.

We are grateful to the Department of Health and Social Security for the financial support which made this study possible. We wish to thank Ms B. Kirkwood for advice on the statistical analysis.

\section{References}

Bisgaard, M., Gregersen, T., and Petersen, E. (1974). Comparative investigations of commercial systems 
available for identification of Enterobacteriaceae. (Danish). Nord. Vet.-Med., 26, 243-247.

Brooks, K. A., Jens, M., and Sodeman, T. M. (1974). A clinical evaluation of the API microtube system for identification of Enterobacteriaceae. Amer. J. med. Technol., 40, 55-61.

Butler, D. A., Lobregat, C. M., and Gavan, T. L. (1975). Reproducibility of the Analytab (API 20E) system. J. clin. Microbiol., 2, 322-326.

Cameron, G. L. (1974). An assessment of the Pathotec rapid I-D system. N.Z. J. med. Lab. Technol., 28, 43-46.

Cochran, W. G. (1950). The comparison of percentages in matched samples. Biometrika, 37, 256-266.

Cowan, S. T. (1974). Cowan and Steel's Manual for the Identification of Medical Bacteria, 2nd edition. Cambridge University Press, London.

Crosby, N. T. (1967). The determination of nitrite in water using Cleve's acid, 1-naphthylamine-7-sulphonic acid. Proc. Soc. Wat. Treat. Exam., 16, 51-55.

Hayek, L. J. and Willis, G. W. (1976). A comparison of two commercial methods for the identification of the Enterobacteriaceae-API 20E and the Enterotubewith conventional methods. J. clin. Path., 29, 158-161.

Lapage, S. P., Bascomb, S., Willcox, W. R., and Curtis, M. A. (1973). Identification of bacteria by computer: general aspects and perspectives. J. gen. Microbiol., 77, 273-290.
Moussa, R. S. (1975). Evaluation of the API, the PathoTec, and the improved Enterotube systems for the identification of Enterobacteriaceae. In New Approaches to the Identification of Micro-organisms, edited by C.-G. Hedén and T. Illéni, pp. 407-420. Wiley, New York.

Nord, C.-E., Lindberg, A. A., and Dahlbäck, A. (1974). Evaluation of five test-kits-API, AuxoTab, Enterotube, PathoTec and R/B-for identification of Enterobacteriaceae. Med. Microbiol. Immunol., 159, 211-220.

Smith, K. E. (1975). An investigation into three rapid multiple-test systems for identification of Enterobacteriaceae and their possible application in a clinical pathology laboratory. Lab. Med., 6, (7), 24-28.

Sneath, P. H. A. (1974). Test reproducibility in relation to identification. Int. J. system. Bact., 24, 508-523.

Sneath, P. H. A. and Johnson, R. (1972). The influence on numerical taxonomic similarities of errors in microbiological tests. J. gen. Microbiol., 72, 377-392.

Snell, J. J. S. and Lapage, S. P. (1973). Carbon source utilization tests as an aid to the classification of nonfermenting Gram-negative bacteria. J. gen. Microbiol., 74, 9-20.

Willis, G. and Cook, I. J. Y. (1975). A comparative study of API, Encise and conventional methods. Med. Technologist, 5, 4-9. 